\title{
In Search of the Generic Identity of the Book Review: A Chronological and Pragmatic Study
}

\author{
Alireza Jalilifar (Ahvaz) and Leila Tanavar (Shiraz)
}

\begin{abstract}
Given the significance of Book Reviews (BRs) and the fact that little has been devoted to the study of this genre, the current study investigated the macrostructure as well as the politeness features of a sample of BRs, representing two periods of time (1980-1990/2000-2010), in applied linguistics. The main purpose of this analysis was to identify the macrostructures and the politeness strategies in the "closing evaluation" section of BRs. The dataset consisted of 80 BRs (40 extracted from the journals published in the 1980s and 40 derived from the journals published in the 2000s). The findings demonstrated no major quantitative differences between the moves exploited in the BRs, except for move 3. Further, positive politeness strategies, characteristic of the "closing evaluation" section, revealed no significant differences deployed in the two groups of BRs, and negative politeness strategies were absent, indicating the non-alignment of these latter strategies to BRs. The analysis of BRs can contribute to both the schema theory and discourse analysis. The study may provide a valuable framework for a comprehensive book review analysis.
\end{abstract}

\section{$1 \quad$ Introduction}

Book reviews (BR) introduce, evaluate, and recommend new books in a particular discipline and assess their value, dependability, and validity with respect to the growth of the discipline (Suarez \& Moreno 2006). BRs can play a pivotal role in fostering scientific knowledge and education for many reasons. First and foremost, BRs inform other researchers of new advances in the discipline on which the text is focused. Secondly, reviewers offer their personal judgments, and therefore they allow readers to gain a second perspective on the matter. Finally, BRs reflect on bare bone essentials of the discussion and scrutinize contents by offering a different view from the editorial review that the book undergoes (Korstanje 2010; Diani 2009).

Book reviews are usually written by the authors who have published several articles, notes, and letters, and they do continue to have more publications (Nicolaisen/Frandsen 2007). From a pedagogic perspective, being the easiest and quickest way to publication, BRs are a good way to enhance the students' writing and analytical skills, learn how the journal publishing process works, and get to know editors (Belcher 2010). Therefore, the review, as part of an academic journal, is an essential genre in not only defining and legitimizing the discipline, but also in legitimizing participation in the professional culture of the discipline (Hyland 2004). If

Linguistik online 72, 3/15 - http://dx.doi.org/10.13092/lo.72.1972

CC by 3.0 
we accept that the main purpose of BRs is to evaluate knowledge, then it can be argued that they are an aid in the acquisition of academic literacy (Babaii/Ansary 2005).

Like other genres, BRs differ with respect to their prototypicality (Swales 1990). Thus, while reviews have received some attention (Becher 1989; Diani 2009; Goggin 2000; Groom 2009; Hyland 2004; Junqueira 2013; Shaw 2009), there has hardly been any full-fledged diachronic study of the genre of reviews in applied linguistics journals except for Giannoni's study of four monographs in applied linguistics for evaluative acts (2009). Reviews deserve further study and, in particular, BRs in well-established applied linguistics journals deserve further exploration as they usually determine the publication norms adopted in the field.

Reviewing presupposes criticism, thus "potentially a face threatening act (FTA), and so it calls for the use of politeness strategies to soften and redress the face threatening act (FTA)" (Jalilifar/Ahmadi 2011:223). The reviewer tries to evaluate the work of a researcher according to different criteria such as adequacy of explanations, usefulness for the prospective reader and possible future implications and applications (Gea Valor 2000-2001: 146). Owing to the fact that evaluation often needs a criticism, a negatively affective speech act which also constitutes the possibility of threatening the addressees' face, mitigation strategies become necessary in order to avoid negative repercussions on the review and make the criticism less incisive. Therefore, along with criticism, the goal is to maintain social harmony and solidarity with the reviewer. This can be acquired by making use of positive politeness strategies which redress the FTAs (Gea Valor 2000-2001). Belcher (1995) studied book reviews for the use of politeness strategies as friendly persuasion and found that the positive commentary which regularly precedes negative assessments aims to soften the force of the face-threatening speech act characteristics of BRs.

Notwithstanding the enormous importance attached to this area of investigation, the study of BRs from a pragmatic perspective has attracted little attention in recent years in comparison with other academic genres such as the research article and the abstract. Therefore, this genre constitutes a prolific area for the study of politeness in academic discourse, as the present study attempts to demonstrate from a diachronic perspective.

BRs have been the subject of conglomerate studies in terms of macro-structure and linguistic features (Babaii 2003; Diani 2009; Groom 2009; Hartley 2006; Junqueira 2013; SalagerMeyer, Alcaraz Ariza/Berbesi 2007; Shaw 2009) or explicit judgments of academic values realized (Giannoni 2009); others have scrutinized BRs for systematic non-linguistic reasons (Cacchiani 2005; Moore 1978; Motta-Roth 1998; Snizek/Fuhrman 1979; Suarez/Moreno 2009; Toledo 2005), negative evaluative expressions by male and female linguists (Cacchiani 2005), exploring politeness strategies (Jalilifar/Ahmadi, 2011), disciplinary differences (Suarez/Moreno 2006), balancing praise and criticism in the assessment of 28 reviews taken from seven different disciplines spanning the arts-science array (Hyland 2000), or authorship in BRs (Salmani Nodoushan/Montazeran 2012).

The only study which has explored the chronological development of reviews is that of Valensky (2010). Valensky studied how reviews reflect the disciplinary trajectory of composition studies diachronically. He studied 90 reviews in the corpus from College English and College Composition and Communication to provide evidence of the historical trajectory of composition reviews. The study showed that reviews reflect the historical, textual, and 
professional development of composition's struggle for disciplinary legitimacy and that reviews in composition studies have shifted over the course of the historical trajectory of composition as it moved from a service course, which is reflected in the short reviews, to a field of study.

Despite the good number of studies on BRs, still we seem not to have sufficient knowledge of the functional organization and evolutionary character of this genre. That is to say, we do not know exactly whether and to what extent the organization of BRs is subject to change across time. Moreover, the studies that have been conducted on politeness features incorporated in BRs have failed to provide conclusive answers as to the nature and function of these micro features. What seems to be evident in the existing literature on BRs is that hardly has any study taken into account BRs diachronically and thus, we do not know if BRs have changed over time.

The book reviewer should also explore and discuss the theme and provide an opinion of the text. The individuals will be informed of a potential perspective on the development of scientific forms of life when we study the evolution of textual practices (Atkinson 1996). What is needed to do more research is the diachronic study of the way BRs have been written. These studies can pave the way for the researchers to become more acquainted with the development of BRs. Investigation into BRs is important in many respects. For example, it can illustrate the reviewers' attitude diachronically. Furthermore, the study can seek the reviewers' use of politeness strategies diachronically. It aims to explore the gradual changes of BRs over two time periods by considering the use of politeness strategies.

The current study pursues two major goals. In the first stage, it provides an extensive analysis of BRs in Applied Linguistics (AL) over two time periods of 1980-1989 and 2000-2010. In the second stage, the study draws on comparing the strategies deployed by book reviewers to avoid threatening the face of the writer. Specifically, the aim is to answer the following questions:

1. To what extent is the generic organization of BRs in Applied Linguistics journals subject to change during the 1980 s and the 2000s?

2. To what extent is the use of politeness features in BRs in Applied Linguistics journals subject to change during the 1980 s and the 2000s?

\section{Materials and Methodology}

In order to fulfill the purpose of this study and investigate the existence of any significant difference(s) between the functional organization and use of politeness features in BRs over two different periods, the current study relied on an appropriate methodology, instrumentation and procedure. This section aims to provide a detailed account of the stages for the administration of the study as well as how the data were subject to analysis.

The data were gathered from the database of the Oxford Journals. Selection of these texts was motivated by their availability to the researchers. First, all the issues of the journals published between 1980-1989 and 2000-2009 were downloaded from the journal websites and the BRs of each volume of the journals were culled to form a dataset for the study. One hundred and sixty ISI journals were listed, from which 50 were selected. Then the list was given to 10 
university lecturers who had $\mathrm{PhD}$ in the field of applied linguistics, and they were then requested to mark only 10 journals based on their personal preferences. As a result, the most preferred journals were respectively picked out as follows:

- Journal of Linguistics

- ESP Journal

- Journal of Pragmatics

- Annual Review of Linguistics

- Applied Linguistics Journal

- $\quad$ Language Testing

Careful surveillance into the contents of these journals revealed that Annual Review of Linguistics does not publish book reviews. Therefore, this journal was removed from the list of the journals, and only five journals remained. In order to narrow down the analysis, we set restrictions on the selection of reviews. Sufficient care was exercised to choose reviews with diverse topics in the field. Also, the length of reviews as well as author diversity constituted the criteria for final selection. Further considerations made in extracting the reviews were:

1) The BR is printed within the time interval specified;

2) The BR is selected from the specified journals;

3) The BR is written by a single author.

The above restrictions helped choose 584 (see Table 1) BRs for the next phase of the study.

\begin{tabular}{|l|c|c|c|}
\hline Journals & $\mathbf{1 9 8 0 - 1 9 8 9}$ & $\mathbf{2 0 0 0 - 2 0 0 9}$ & Total \\
\hline ESP Journal & 17 & 89 & 106 \\
\hline Journal of Linguistics & 20 & 20 & 40 \\
\hline Journal of Pragmatics & 27 & 222 & 249 \\
\hline Language Testing & 19 & 36 & 55 \\
\hline Applied Linguistics Journal & 67 & 67 & 134 \\
\hline Total & 150 & 434 & 584 \\
\hline
\end{tabular}

Table 1: Frequency of BRs Within the Specified Interval

Finally, eight BRs were randomly selected from each journal in each decade. This systematic selection process helped choose 80 reviews, representing the BRs published within the two periods in focus. The reviews were codified to keep the identity of the BR writers confidential.

\section{$3 \quad$ Data Analysis}

Following the data collection, in the next stage the functional features of the selected BRs, or the communicative moves, were identified. The theoretical frameworks selected for this study were the models suggested by Motta Roth (1998) and Swales (1990). That is, analysis started with the texts, in the light of the above models, codifying each part moving way up to verifying the established frameworks. Two other researchers working in this area were asked to comment on the reliability of coding, although one of the researchers declined our request. After an agreement was made on the method of analysis, other texts were analyzed 
A Chronological and Pragmatic Study

accordingly. Following the analysis, the texts representing the two periods were compared for the presence or absence of moves as well as politeness features.

The methodology employed in the present study is directed to answering the aforementioned research questions. Our functional analysis of the BRs helped to identify four moves or communicative functions, and a number of constituting steps or linguistic realizations. The moves were identified by inferring the rhetorical functions developed by various sections in the entire text in connection with the overall purpose of the text.

The first move, "introducing the book", includes four variations. The first subfunction, "defining the general topic of the book", shows the change from the general topic of the book being reviewed to a more specific aspect of its content. The second subfunction, "informing about potential readership", shows the benefiters. The third subfunction, "inserting the book in the field", indicates previous works done in the same field. The last subfunction of this move, "informing about the author", comprises information about the author's life. The next move, "outlining the book", comprises four variations too. "Providing an overview of the organization of the book" gives a general view about the arrangement of different parts of the book under review. "Stating the topic of each chapter" is the second subfunction of outlining the book. "Describing the book" as the next subfunction provides an account of each chapter separately or generally. The last step of this move, "citing extra text material", shows indexes, tables or appendixes used in the book under review. The next move, "highlighting parts of the book", contains one subfunction, "providing focused evaluation" that evaluates different parts of the book under review. The fourth move is "providing closing evaluation" with six variations as follows: "Definitely recommending the book", "recommending the book despite indicated shortcomings", "not recommending the book despite indicated strengths", "suggesting for further investigation" which was not found in Motta Roth's framework, "providing neutral summary-conclusion of book" and the last variation of this move which was not included in Motta Roth is "disqualifying the book".

The principal procedure for analyzing the data in this study was comparative. For the first part of the study, the functional moves of the BRs in the two periods were compared to see if they adopt similar patterns. The Frequencies of each move or strategy were counted and Chisquare was run to see whether possible differences were statistically significant. In the next stage, qualitative analyses provided richer and deeper insights into the function of each move or strategy.

Inspired by the importance of politeness strategies in BRs and the fact that little attempt has been dedicated to highlighting how these strategies are incorporated into these texts, the current study also scrutinized politeness features in "the closing evaluation move", based on Brown and Levinson's (1987) theory of politeness. The restriction imposed on this part of the study was motivated by the instances of the politeness strategies that were identified only in the "evaluation move".

Different kinds of theoretical models have been proposed, and usually they have been defined as abstract terms, directly or indirectly referring to a wide array of social strategies for constructing co-operative social interaction. As we have seen, book reviewing is a potentially face-threatening act since it basically involves the assessment of a colleague's work, and it should be amalgamated with softening devices to redress the effect of FTAs (Brown/Levinson 
1987: 101). Through reviewing a work, the reviewer should combine mitigating strategies with his critical viewpoints to achieve communicative balance and to negotiate meaning via written discourse. This helps other readers of these works to be acquainted with an unbiased critique which is an effective tool to promote an authentic context for real communication and development of learning (Hyland/Diani 2009). A large number of theoretical and empirical books and articles concerning linguistic politeness have been published over the last decades. In most of the studies, politeness has been conceptualized especially as strategic conflictavoidance or as strategic construction of cooperative social interaction. According to Brown and Levinson, positive face reflects the desire to have one's possessions, goals, and achievements desired by a socially or situationally relevant class of others; thus, positive politeness expresses either a general appreciation of the addressee's wants or similarity between the wants of the speaker and addressee $(1987: 63,101)$.

Another researcher working in this area was also asked to comment on the reliability of coding in this stage. Having reached an agreement over analysis, the "closing evaluation" of the 80 book reviews was carefully scrutinized. This analysis helped to identify only positive politeness strategies. The study acknowledges the absence of "negative politeness" in the "closing evaluation" of the book reviews in the specified periods.

\section{$4 \quad$ Results and Discussion}

\subsection{Functional Move Analysis of BRs}

The current study sought to uncover the move structure of the BRs written within the specified interval. The analysis involved multiple readings of each BR and counting the frequency of occurrence of each move. The frequencies in the table that follows represent tokens typical of each move or step. The structure of BRs is made up of four moves as illustrated in Table 2.

\begin{tabular}{lcccc}
\hline Moves and steps & 1980s frequency & \% & 2000s frequency & \% \\
\hline Move 1: Introducing the book & 39 & 97.5 & 39 & 97.5 \\
Step 1: defining the general topic of the book & 12 & 30 & 12 & 30 \\
Step 2: informing about potential readership & 17 & 42.5 & 13 & 32.5 \\
Step 3: inserting the book in the field & 16 & 40 & 16 & 40 \\
Step 4: informing about author & 1 & 2.5 & 2 & 5 \\
Move 2: Outlining the book & 34 & 85 & 28 & 70 \\
Step 1: providing an overview of the organization & 11 & 27.5 & 15 & 37.5 \\
of the book & & & & \\
Step 2: stating the topic of each chapter & 26 & 65 & 8 & 20 \\
Step 3: describing the book & 28 & 70 & 15 & 37.5 \\
Step 4: citing extra text material & 4 & 10 & 3 & 7.5 \\
Move 3: Highlighting parts of the book & 30 & 75 & 19 & 47.5
\end{tabular}


A Chronological and Pragmatic Study

\begin{tabular}{llllc} 
Step 1: providing focused evaluation & 30 & 75 & 19 & 47.5 \\
Move 4: Providing closing evaluation of the book & 40 & 100 & 38 & 95 \\
$\begin{array}{l}\text { Step 1: definitely recommending the book } \\
\text { Step 2: recommending the book despite indicated }\end{array}$ & 19 & 47.5 & 19 & 47.5 \\
$\begin{array}{l}\text { shortcoming } \\
\text { Step 3: suggesting for further investigation }\end{array}$ & 2 & 22.5 & 11 & 27.5 \\
$\begin{array}{l}\text { Step 4: providing neutral summary-conclusion of } \\
\text { the book }\end{array}$ & 8 & 5 & 0 & 0.0 \\
Step 5: disqualifying the book & 2 & 5 & 4 & 12.5 \\
\hline Total & $\mathbf{3 2 7}$ & & $\mathbf{2 5 4}$ &
\end{tabular}

Table 2: Frequency of the Functional Moves and Constituting Steps in BRs

BR writers often use move 1 to give a description of the book. This description is often in the form of an informative abstract or as an introduction to the book under review; writers normally give a short account of the content of the book. Move 1 was the most frequent included in $97.5 \%$ of the BRs. This move is considered as conventional in this study, though in other studies it was taken to be optional (e. g., Salmani Nodoushan/Montazeran 2012; Suarez/Moreno 2006). According to Rasmeenin (2006), an obligatory move occurs in all instances of a genre whereas a conventional move is imminent in more than 70 percent and an optional move is present in less than 70 percent of the instances of a genre. In another study, however, Babaii (2003) claimed that Move 1 was present in all the BRs that were analyzed hence considered as obligatory. Move 1 is very often composed of one or a combination of the steps. As demonstrated in Table 3, the defining feature of the two groups of BRs is laid in step 2, where there seems to be a growing tendency among the BR writers to address their readers. Note the following examples that illustrate the steps in Move 1:

M1S1:

1) Productivity is a vexed question in morphology, intimately related to notions of regularity, creativity, frequency and so on, but not reducible to any of these. Indeed, it isn't even clear whether the phenomenon should be treated as linguistic or extralinguistic (or both). Bauer has provided us here with a very helpful survey of the issues and of recent research, including psycholinguistic and corpus-based statistical studies. The book consists of seven chapters and includes a separate language and subject index.

\section{M1S2:}

2) The book is intended for linguists (or linguistics students) who have little or no knowledge of any sign language but do have grounding in theoretical linguistics (particularly in generative frameworks). Thus, it is quite different from typical sign linguistics textbooks (e. g. Valli/Lucas 1995; Sutton-Spence/Woll 1999) which are aimed at students who know or are learning sign language and have no background in linguistics. 
M1S3:

3) A book on language testing with the subtitle a practical approach is presumably aimed at teachers, although the authors do not stress this point in their preface. It is thus a rival to earlier books such as those of Harris (1969) and Heaton (1975), and to such recent classroom testing handbooks as those of Harrison (1983) and Madsen (1983).

M1S4:

4) David P. Harris is Professor of Linguistics at Georgetown University. He was the first program director of the Test of English as a Foreign Language (TOEFL) and has written a variety of EFL tests and instructional materials on language testing. He is a member of the editorial advisory board of The ESP Journal.

Since the difference in the frequency of this move between the two groups of the BRs was less than five, therefore, no test of difference was administered. In other words, writers give a short account of the book under review in a fairly similar manner following roughly the conventional steps mentioned in the literature.

Delineating the book under review, "outlining the book" is usually the longest move and appears in a number of paragraphs close to the beginning of the BR. According to Motta-Roth (1995), this move presents a detailed description of how the book is organized in terms of parts, chapters, sections, and so on. Moreover, the move provides information in relation to what topics are treated in each chapter, which approach has been adopted by the author of the book, and what additional information is included in the book (i. e., graphs, pictures, and tables). Move 2 was realized through four steps as indicated in Table 3 above. Generally speaking, this move was identified in majority of the BRs though more frequently in the earlier BRs $(85 \%)$ than the more recently published ones $(70 \%)$. Step 2 for the latter group was employed three times less than that for the former BRs (26 vs 8). Likewise, as far as step 3 is concerned, the frequency of occurrence for the recent BRs amounted to about half that quantity for the former BRs. The decline in the steps for the new BRs can be interpreted in two ways. First, the length of the new BRs in terms of the words per BR may show a reduction (i. e., older volumes of journals would tend to publish longer BRs). Second, the authors may prefer to dedicate more space to criticizing the book under review. This is a point which calls for further research. Move 2 in Suarez and Moreno (2006) is characterized by three steps whereas the current study identified a fourth step ("describing the book"). Analyzing the BRs in this study categorizes Move 2 as conventional (Rasmeenin 2006) though in other studies Move 2 is recognized as optional (Babaii 2003; Suarez/Moreno 2006). Note the following examples of the steps characterizing Move 2:

M2S1:

5) The book is divided into two major parts. The first part focuses on the theory and politics of EAP with chapter one providing a chronology of the various historical stages of EAP from its inception in the 1960s. Here Benesch highlights a number of issues such as needs analysis, linked courses and genre analysis, which set the stage for her subsequent critical investigations. While this chapter applauds EAP's readiness for change and 'sensitivity to contexts' (p. 23) it intentionally presents us with the politically neutral view of EAP as an inevitable series of events. This accentuates the discussion in the second 
Alireza Jalilifar and Leila Tanavar :In Search of the Generic Identity of the Book Review:

A Chronological and Pragmatic Study

chapter, which shows how the ideologies of EAP are far from neutral and have in fact been shaped by particular political and economic circumstances.

M2S2:

6) The first part of Handbook, entitled 'Foundations', contains six chapters dealing with issues with issues fundamental to the early stage of test development. In the first chapter, 'Twelve Steps for Effective Test Development', Steven Downing summarizes the process of test development in 12 steps: overall plan, content definition, test specification, item development, test design and assembly, to test production, administration, scoring, establishing cut scores, reporting results, item banking, and finally test technical report. He insists that for the sake Downloaded from ltj.sagepub.com at MCGILL UNIVERSITY LIBRARY on Jun 29, 2013422 Book review of validity, 'effective test development requires a systemic, well organized approach' (p. 3). Robert Linn, in the following chapter, 'The Standards for Educational and Psychological Testing: Guidance in Test Development', links the Standards to their real-life use in the testing situation and in different parts of the testing process. In the third chapter, 'Contracting for Testing Services', E. Roger Trent and Edward Roeber provide a 'procurement processes for people, agencies, or institutions that are looking into contracting an agency for their testing needs. They discuss three steps: planning, writing up the request for proposals, and finally evaluating potential offers/bids, and drafting and negotiating contracts. Robert Mislevy and Michelle Riconscente in Chapter 4, 'Evidence-Centered Assessment (ECD) Design', advocate bringing all aspects of testing together and allowing knowledge and information to circulate among the testing machine, that is, the bureaucracy. They present five layers in the ECD process: Domain Analysis, Domain Modeling, Conceptual Assessment Framework, Assessment Implementation, and Assessment Delivery. In the fifth chapter, 'Item and Test Development Strategies to Minimize Test Fraud', James Impara and David Foster tackle test fraud from two sides: cheating and test piracy, and offer eight strategies to reduce fraud. In the last chapter in this part, 'Preparing Examinees for Test Taking: Guidelines for Test Developers', Linda Crocker discusses preparing K-12 students for large-scale exams.

M2S3:

7) RK's work can be read on different levels, and with different optics. On one level, one could read it as a fascinating account of the birth and revival of the Hebrew language, centered around the mythical figure of Eliezer Ben-Yehuda, whose status as the man, who single-handedly brought Hebrew back to life, is critically examined through a scrutiny of his life and works. One could also read the book as a treatise in alternative approaches to a common problem, by showing how the divergent views of Judaism vs. Hebrew-ness manifest themselves in the protagonists of a secular vs. a religious 'nation', in contrast to the monolithic view of Zionism, by which Jew and Hebrew, state and nation, religion and state are considered to be intricately connected and almost synonymous in practice.

M2S4:

8) The three appendices, which together make up about a third of the book's volume, provide detailed guidance on how to assemble a CDP and contain ample further 
materials (such as sample PowerPoint presentations on cultural aspects of presentation and meeting practices) that can be used to promote reflective self-assessment among organizational employees.

Calculating the chi-square test for this move signaled no statistically meaningful difference between the two decades. (See Tables 3 and Table 4 for descriptive and inferential statistics).

\begin{tabular}{lccccc}
\hline Move 2 & N & Minimum & Maximum & Mean & Std. Deviation \\
\hline First decade & 4 & 4.00 & 28.00 & 17.2500 & 11.64403 \\
Second decade & 4 & 3.00 & 15.00 & 10.2500 & 5.85235 \\
Valid N (list wise) & 4 & & & & \\
\hline
\end{tabular}

Table 3: Descriptive Statistics of Move 2

\begin{tabular}{lccc}
\hline & $\mathrm{X}^{2}$ & df & sig. \\
\hline Chi-square & 7.58 & 3 & 0.0555 \\
\hline
\end{tabular}

$\mathrm{P}<0.05$

Table 4: Chi-square Test of Move 2

In "Providing focused evaluation", reviewers usually point out positive and negative remarks on specific aspects of a book in order to give the reader a clear idea of their opinion on the book. Through Move 3, authors often highlight the advantages and disadvantages of a book, give a summarized account of what caught their attention, identify the criteria which they followed, present their reasons for their evaluation (sometimes through intertextuality), and give examples from the book to sustain their evaluation. This Move was realized in only one step in the current study like in Suarez and Moreno (2006). Contrary to Babaii (2003) with only $13.82 \%$ of Move 3 and categorizing it as an optional move, Move 3 with $75 \%$ was regarded as conventional in the current study.

Move 3 is sometimes incorporated in move 2 when the reviewer clearly aims at describing the chapters of a book and provides focused evaluation on them at the same time. Note the following example:

9) The last chapter of Part One (Stress and Rhythm) largely ignores intonation. In the introduction, Valdman states that 'no satisfactory theory has been proposed to account for intonational distinctions in French' and that 'no coherent and simple description is yet possible for that area of phonology'. Even though some sketchy treatment of intonation could probably have been accomplished, Valdman does have a point; yet, this is a rather crucial area for the language learner, and this situation again emphasizes the need for illustrative aural material.

The above example is outlining as well as evaluating the last chapter of a book under review (Move 3). Though statistically not meaningful, results reveal a marked decline in using this move. Results from the analysis $\left(\mathrm{X}^{2}=11.325, \mathrm{X}_{\mathrm{c}}{ }_{\mathrm{c}}=3.841\right.$, sig=0.032) indicated no significant difference between the BRs of the two groups in the study. 
A Chronological and Pragmatic Study

\begin{tabular}{lccc}
\hline & $\mathrm{X}^{2}$ & $\mathrm{X}_{\mathrm{c}}$ & sig. \\
\hline Chi-square & 11.325 & 3.841 & 0.032 \\
\hline
\end{tabular}

Table 5: Chi-square Test of Move 3

In move 4 which is commonly reserved for the last paragraph in the review, the author uses textual markers to signal to the reader that the review is approaching its end. In this final move, the reviewer's point of view is overtly stated to the reader through a definitive appraisal of the book (Motta-Roth 1995). The reviewer tells the reader whether the book is worth reading or not. In other words, in this move the writer makes suggestions whereas in Move 3, the reviewer gives an evaluation of the book (i.e., evaluation versus suggestion/recommendation). Sometimes, Move 4 also provides a final evaluation. Thus, in addition to functioning as a recommendation for the reader, this move also serves the purpose of closing the text (Motta-Roth 1995). It rounds up the text in a final evaluation of the whole book by breaking up with the detailed perspective adopted in Move 3.

According to Motta-Roth (1995), the lexical phrases which are often found in this move convey an idea of totality and termination, including altogether, in summary, in conclusion, finally etc. In addition, sometimes reviewers use lexical phrases to convey a type of evaluation; examples of these phrases are an important contribution, a stimulating/an excellent book and the like. Other phrases used in this move are expected to take into account what the reviewer has formerly said throughout the review (e. g., thus, despite, in spite of, etc.). Move 4 has a two-fold function: closing the BR and giving a definite opinion on the overall value of the book. The evaluation of this last part of the review differs from the evaluation of move 3 in that the former is taken to be more general. It is usually a summary of what has previously been said and aims at justifying the final verdict on the book. Through the use of this move, the reviewer adopts one of the five possibilities: "definitely recommending the book" consists in a blunt recommendation of the book, sometimes even after having expressed negative evaluation in previous parts of the review; "recommending the book despite indicated shortcomings" consists in giving a favorable verdict on the book being reviewed but highlighting some negative points at the same time; "suggesting for further investigation" consists in giving lines for further research about the book, "providing neutral summary conclusion of the book" consists in closing the review through a mere summary or conclusion of the book with no evaluation at all, and "disqualifying the book" definitely implies a total rejection of the book reviewed. Suarez and Moreno (2006) called this step "definitely not recommending the book" instead of "disqualifying the book". The following examples illustrate the above steps in move 4:

M4S1:

10) In all, Genre and Second Language Writing is an excellent introduction to genre-based literacy instruction. It demystifies how the analysis and teaching of genre is done with different student populations and from different theoretical perspectives. In doing so, Hyland's book will well serve all of its intended audiences - new and experienced teachers, and even genre teaching skeptics. 
M4S2:

11) The book does, however, explicitly discuss our value-systems and there are frequent mentions of ethical issues such as the impact of feedback from teachers on the professional lives of course participants. The book's main contribution to the profession, however, is in widening our repertoire of skills. This is its greatest strength and it is for this that it deserves a place on our shelves.

M4S3:

12) Where might these research directions lead? An emerging result is a description of the complex decision making, conflicting personal interpretations, varied knowledge sources, and key text features that combine to constitute the assessment of writing. This information can guide the orientation and professional development of composition assessors as well as the design of evaluation instruments and rubrics. I also expect to see much future research, akin to Lumley's on formal writing tests, on other aspects of language assessment, providing insights into thinking processes during, for example, teachers' formative assessments of their students' writing (Ferris 2003) or oral interviews or other assessment tasks (Fulcher 2003).

M4S4:

13) In conclusion, this book is a stimulating discussion of a complex phenomenon of considerable interest both on a syntactic and a pragmatic level Book reviews 819 even though the detailed analysis of the corpus is more substantial than the theoretical considerations, which are interspersed with the author's discussion of the data.

M4S5:

14) The volume also suffers from a conspicuous lack of cohesion. Not all of the chapters can be thought of as pieces defending the practice of testing, and do not always adhere to the theme given in the book's title. The reader is left with the impression that the various authors were commissioned to contribute on a topic but not given guidelines that would aid in tying the chapters together. The result is an awkward hodgepodge that, in my opinion, is the book's biggest weakness. Again, there is useful information in the various chapters, but one should not expect to find a well-articulated set of papers defending testing.

\begin{tabular}{lccccc}
\hline Move 4 & N & Minimum & Maximum & Mean & Std. Deviation \\
\hline First decade & 6 & .00 & 19.00 & 6.6667 & 7.03325 \\
Second decade & 6 & .00 & 19.00 & 6.5000 & 7.34166 \\
Valid N (list wise) & 6 & & & & \\
\hline
\end{tabular}

Table 6: Descriptive Statistics of Move 4

Our research revealed the frequency of this move to be almost equally exploited in both groups, and so no significant difference could be statistically observed (40 vs 38 ). Since the difference between the frequencies of each step in the two groups was less than five, therefore, no inferential statistics was utilized. Results acknowledge the consistency of BR 
A Chronological and Pragmatic Study

writers in providing an appraisal of the book in focus and that the writers' attitude toward including/excluding evaluation has remained relatively stable. Like in Rasmeenin (2006), Move 4 in the BRs of the $80 \mathrm{~s}$ is considered obligatory whereas in the BRs of the $2000 \mathrm{~s}$, it is regarded to be conventional. This is in stark contrast to Babaii (2003) in which Move 4 is seen as optional (15.90\%). Similarly, Babaii (2003) in her study concluded that while native English-speaking authors had a tendency toward writing evaluative reviews, non-native BR writers preferred to write informative BRs more frequently. In the current study, both groups of the BRs demonstrated similar trends in writing evaluative BRs.

\subsection{Analysis of the Politeness Strategies in BRs}

In today's academic world, BRs have become an effective means to present new studies in a scientific field and to assess their validity as relevant contributions to the progress of the discipline. The assessment of a colleague's work necessarily involves criticism- a potentially face-threatening act (FTA) - and it therefore calls for the use of politeness strategies to soften and redress the FTA. Thus, drawing on the face model proposed by Brown and Levinson (1987), the current study compared the "closing evaluation" of BRs in terms of politeness strategies both qualitatively and quantitatively. The result revealed that politeness strategies were similarly treated in the BRs representing the two decades, and so no significant differences were observed. Interestingly, negative politeness strategy, off-record, and bald-onrecord did not attract the attention of BR writers. The examples that follow demonstrate the application of positive politeness strategies in BRs.

15) The overall quality and ultimate effectiveness of these materials are unquestionable.

16) The collection as a whole, then, is a useful one in highlighting significant uncertainties in the practice of CP at a number of analytical levels, and is particularly welcome as a rare cross-section of recent research on phonological acquisition and contrast.

17) Wallace's book is a comprehensive, well-written, and understandable guide for all those who are interested in the design of natural language front ends to databases.

In the above examples, the compliment strategy is recognized. A compliment is a speech act which "explicitly or implicitly bestows credit upon the addressee for some possession, skill, characteristic, or the like, that is positively evaluated by the speaker and the addressee" (Holmes 1988: 446). In analyzing the BRs in this study, the compliment and marketing strategies were recognized as tokens of positive politeness exploited by the BR writers to increase the marketing value of the book.

\begin{tabular}{|l|c|c|c|c|}
\hline Politeness strategy & $\mathbf{1 9 8 0 s}$ & $\boldsymbol{\%}$ & $\mathbf{2 0 0 0 s}$ & \% \\
\hline Positive politeness strategy & 40 & $100 \%$ & 40 & $100 \%$ \\
\hline
\end{tabular}

Table 7: Researcher-made Frequency of Politeness Strategy

\section{Conclusion}

The present study investigated the communicative aspects of BRs in applied linguistics. The study was comparative, using two sets of data spanning over two different decades. The aim 
was to find the generic structure and politeness strategies in BRs and how they are treated in specified time intervals. The results of the move structure analysis indicated similarities and differences between the two groups.

Overall, the findings of the current study exhibited that, in the recent BRs the authors' tendency to shorter BRs increased. This can be clearly witnessed in Steps 2 and 3 of Move 2 and also in Move 3 (Table 3). In the former BRs, the frequency of Step 2 in Move 2 is 65\% vs $20 \%$ in the latter BRs. Likewise, Step 3 in the same move with $70 \%$ in the former BRs was found to be about twice the number in the latter BRs. This analysis revealed that older BRs make greater use of this move and step in comparison with the more recent BRs. Also, the frequency of Move 3 (highlighting parts of the book) in the recent BRs is about twice less than Move 3 in the former BRs showing a gradual reduction in the length of the BRs.

As for politeness strategies, results indicated similarities in exploiting politeness strategies between the two groups of BRs. A marked finding in this study is the absence of negative politeness, bald-on-record and off-record strategies in the BRs under investigation. Compliment and marketing strategies as tokens of the politeness strategies were found almost similarly treated.

By comparing the functional structure of tokens of a genre belonging to different time intervals, researchers can trace genre resemblances as well as chronological changes in structure. Awareness of genre conventions in a discourse community is a necessity which must be taken up by writers in different contexts. Indeed, by virtue of what was articulated by Bhatia (1993: 1), "successful achievement of communicative purposes outlined in a specific discourse community depends on such communicative purposes using conventionalized knowledge of linguistics and discourse recourses".

The analysis of BRs, which was part of the concern of this study, can contribute to both the schema theory and discourse analysis. To actualize the text as discourse, Martinez (2008) claims that systematic knowledge will contribute to relate the schematic knowledge to the textual clues. Moreover, analysis of BRs helps reviewers, readers, and other BR researchers to promote the schema theory. By understanding the context of the book, the schema theory develops and plays a crucial role in how a text is read.

Findings from this study can have important implications for academic writing courses, because they help to predict the possible rhetorical inefficiency of the BRs written during the specified time interval. Understanding the cultural and social context in which meaning will need to emerge in academic book reviewing situations should help to orient the kind of training needed in academic writing courses that include this genre both in 1980s and 2000s. As a final point, this study may benefit both BR writers and journal editors. Familiarity with the structure of BRs creates an awareness of which moves can, which moves cannot and which moves must be used in writing a BR. Moreover, awareness of the structure of BRs helps journal editors to choose those BRs for publication which increase chances of promoting their journals.

The data examined in this study comprised 80 BRs collected from applied linguistic journals. Even though this is not a small number, in order to claim more valid generalizability of the results, the corpora to be examined in future studies should be enriched by adding data from 
A Chronological and Pragmatic Study

other journals and a larger number of BRs. We are convinced that, with a larger corpus, decisions regarding those conventionalized and less frequent moves or steps can be made using more valid generalizations. BR is a genre that might be exploited in many, if not all, disciplines. The knowledge of how BRs are written in different disciplines is of overarching importance to those interested in genre studies. Besides, cross-cultural investigations can be conducted in order to see how cultural specificities might affect the formation of BRs and whether the overall organization of a BR would remain intact across different cultures and languages.

\section{References}

Atkinson, Dwight (1996): "The philosophical transactions of the royal society of London, 1675-1975: A socio-historical discourse analysis". Language in Society 25: 333-371.

Babaii, Esmat (2003): Towards an analysis of book reviews as an academic written genre. Unpublished Master's Thesis, Shiraz University.

Babaii, Esmat/Ansary, Hasan (2005): "On the effect of disciplinary variation on transitivity: The case of academic book reviews". Asian EFL Journal 7/3: 113-126.

Becher, Tony (1989): Academic tribes and territories: Intellectual inquiry and the cultures of disciplines. Milton Keynes: SRHE/OUP.

Belcher, Diane (1995): "Review on academic writing for graduate students". English for Specific Purposes 14: 175-179.

Belcher, Luis (2010): Writing the academic book review: Intellectual inquiry and the cultures of disciplines. Milton Keynes: SRHE/OUP.

Bhatia, Vikay (1993): Analysing genre: Language use in professional settings. London: Longman.

Brown, Penelope/Levinson, Stephen (1987): "Universals in language usage: Politeness phenomena". In: Goody, Esther (ed.): Questions and politeness. Cambridge, Cambridge University Press: 324-356.

Cacchiani, Silvia (2005): "Local vehicles for intensification and involvement: The case of English intensifiers". In: Cap, Piotr (ed.): Pragmatics today. Frankfurt/Main, Peter Lang: 401-419.

Diani, Giuliana (2009): "Reporting and Evaluation in English Book Review Articles: A Cross-Disciplinary Study". In: Hyland, K/Diani, Giuliana (eds): Academic evaluation: Review genres in university settings. London, Palgrave Macmillan: 87-104.

Gea Valor, Ma Lluisa (2000-2001): "The pragmatics of positive politeness in the book review". RESLA 14: 145-159.

Giannoni, Davide Simone (2009): "Negotiating research values across review genres: A case study in applied linguistics". In: Hyland, Ken/Diani, Giuliana (eds): Academic Evaluation: Review genres in university settings. London, Palgrave Macmillan: 17-33.

Goggin, Maureen Daly (2000): Authoring a discipline: Scholarly journals and the post-world war II emergence of rhetoric and composition. Mahweh, NJ: Lawrence Erlbaum.

Groom, Nicholas (2009): "Phraseology and epistemology in academic book reviews: A corpus-driven analysis of two humanities disciplines". In: Hyland, Ken/Diani, Giuliana(eds): Academic Evaluation: Review genres in university settings. London, Palgrave Macmillan: 122-139. 
Hartley, James (2006): "Reading and writing book reviews across disciplines: Research articles". Journal of the American Society for Information Science and Technology 57: 1194-1207.

Hyland, Ken (2000): Disciplinary discourses: Social interactions in academic writing. London: Pearson.

Hyland, Ken (2004): "Engagement and disciplinarity: The other side of evaluation". In: Del Lungo Camiciotti, Gabriella (ed.): Academic discourse: New insights into evaluation. Amsterdam, Peter Lang: 13-30.

Hyland, Ken/Diani, Giuliana (2009): "Introduction". In Hyland, Ken/Diani, Giuliana (eds): Academic evaluation: Review genres in university settings. New York, Palgrave Macmillan: 1-14.

Jalilifar, Alireza/Ahmadi, Narges (2011): "Towards an analysis of review genres: An investigation of macro and micro structures". In: Jalilifar, Alireza/Abdollahzadeh, Esmaeel (eds.): Academic research genres in an Asian context. Ahvaz, Shahid Chamran University of Ahvaz Press: 223-244.

Junqueira, Luciana (2013): "A genre-based investigation of applied linguistics book reviews in English and Brazilian Portuguese". Journal of English for Academic Purposes 12: 203-213.

Korstanje, Maximiliano (2010): "The importance of book review in tourism and hospitality". E-Review of Tourism Research (eRTR) 8/4. http://ertr.tamu.edu [09.02.2014].

Moore, Michael (1978): "Discrimination or favoritism? Sex bias in book reviews". American Psychologist, 33/100: 936-938.

Moreno, Ana (2008): "The importance of comparable corpora for cross-cultural studies". In: Connor, Ulla/Nagelhout, Ed/Rozycki, William (eds): Contrastive rhetoric: Reading to intercultural rhetoric. Philadelphia, Benjamins: 25-41.

Motta Roth, Desiree (1995): Book reviews and disciplinary discourses: Defining a genre. Proceedings of the TESOL 29th Annual Convention/Exposition. Long Beach, CA: 385-386.

Motta-Roth, Desiree (1998): "Discourse analysis and academic book reviews: A study of text and disciplinary cultures". In: Fortanet, Inmaculada/Posteguillo, Santiago/Palmer, Juan Carlos et al. (eds.): Genre studies in English for academic purposes. Publicación de la Universidad de Jaume I: 29-59.

Nicolaisen, Jeppe/Frandsen, Tove Faber (2007): "The handicap principle: A new perspective for library and information science research". Information Research 12: 1-12.

Rasmeenin, Chawalee (2006): A structural move analysis of MA thesis discussion sections in applied linguistics. Unpublished Master's Thesis, Mahidol University.

Salager-Meyer, Francoise/Ariza, Alcaraz/Angeles, Maria et al. (2007): "Collegiality, critique and the construction of scientific argumentation in medical book reviews: A diachronic approach". Journal of Pragmatics 39: 1758-1774.

Salmani Nodoushan, Mohammad Ali/Montazeran, Hamed (2012): "The book review genre: A structural move analysis". International Journal of Language Studies 6/1: 1-30.

Shaw, Philip (2009): "The lexis and grammar of explicit evaluation in academic book reviews, 1913 and 1993". In: Hyland, Ken/Diani, Giuliana (eds): Academic evaluation: Review genres in university settings. London, Palgrave Macmillan: 217-235. 
A Chronological and Pragmatic Study

Snizek, William/Fuhrman, Ellseworth (1979): "Some factors affecting the evaluative content of book reviews in sociology". The American Sociologist 14: 108-114.

Suárez, Tejerina/Moreno, Ana (2006): "The rhetorical structure of academic journal book reviews: A cross-linguist and cross-disciplinary approach". In: Perez-Llantada Auria, Carmen/Plo-Alastrue, Ramon/Neumann, Claus Peter (eds.): Proceedings of the 5th International AELFE Conference. Zaragoza: Prensas.

Suárez, Lorena/Moreno, Ana (2009): "Academic book reviews in English and Spanish: Critical comments and rhetorical structure". In: Hyland, Ken/Diani, Giuliana (eds): Academic evaluation: Review genres in university settings. London, Palgrave Macmillan: 161-178.

Swales, John (1990): Genre analysis: English in academic and research settings. Cambridge, Cambridge University Press.

Toledo, Filho (2005): "Genre analysis and reading of English as a foreign language: Genre schemata beyond text typologies". Journal of Pragmatics 37: 1059-1079.

Valensky, Sandra (2010): Composition under review: A genre analysis of book reviews in composition, 1939-2007. Doctoral Dissertation, Wayne State University. http://digitalcommons.wayne.edu/oa_dissertations/134 [20.03.2014]. 